\title{
Triceps activation amplitudes during functional activities
}

\author{
Abstract \\ Objective: To investigate the muscular activation amplitudes of three regions of triceps \\ musculature during functional activities. We hypothesized that the medial and lateral triceps \\ would be greatest in the terminal $30^{\circ}$ arc of extension activities. \\ Design: Cross sectional. \\ Setting: Musculoskeletal Clinical Laboratory. \\ Participants: 20 healthy subjects recruited from a sample of convenience. \\ Intervention: Fine wire electromyograhical (EMG) electrodes were placed into the medial, \\ central, and lateral triceps to measure muscular activation amplitude and two dimensiona \\ electrogoniometric kinematic activity was recorded during functional activities associated \\ with activities of daily living.
}

Main Outcome Measure(s): Root mean squared amplitudes of triceps muscles normalized to maximal voluntary isometric contractions that are sub-divided into $30^{\circ}$ arcs of motion.

Results: The medial triceps generated significantly more EMG activity during the terminal $30^{\circ}$ arc of supine extension $(54 \pm 11 \% \mathrm{MVIC}, \mathrm{p}<.05)$ and during the pushing activity $(29 \pm 7 \%$ MVIC, $\mathrm{p}<.01)$. The lateral triceps remained relatively constant throughout all arcs, while the central triceps consistently generated the lowest EMG activation level across all functional tasks.

Conclusion: The hypothesis is partially supported as the medial triceps generated more activity in two of the three tasks during the terminal $30^{\circ}$ of extension. The lateral portion is activated consistently throughout the extension motion and acts as a dynamic stabilizer during extension activities. These results indicate that the constant activity of the lateral insertion of the triceps, in conjunction with the terminal extension activity of the medial insertion, play a primary role in terminal elbow extension, especially in anti-gravity and load bearing activities. This new data has implications for surgical approaches to the elbow, management of elbow injuries, and rehabilitation of this joint.

Keywords: fine wire electromyography, activities of daily living, elbow joint
Volume 2 Issue 5 - 2015

\author{
Srinath Kamineni, Corey Gildea, Art Nitz,Tim \\ L Uhl \\ Department of Orthopaedics and Sports Medicine, University of \\ Kentucky, USA
}

\author{
Correspondence: Tim L Uhl, 210c Charles T.Wethington \\ Building, 900 South Limestone, Lexington, KY 40536-0200, \\ Kentucky, USA, Tel 859-218-0858,
}

Email srinathkamineni@gmail.com

Received: April 07, 2015 | Published: May II, 2015
Abbreviations: TEA, Total Elbow Arthroplasties; RMS, Root Mean Squared; EMG, Electromyographical; MVIC, Maximal Voluntary Isometric Contraction

\section{Introduction}

There is an increasing frequency of total elbow arthroplasties (TEA) being performed, however with this increase there is a relatively high complication rate of $24 \% .^{1}$ The highest complication rates were associated with component loosening and joint instability. Triceps complications averaged $2.4 \%$ but were thought to be underreported. ${ }^{1}$ In the presence of triceps complications, loss of overhead active elbow extension and the inability to push open a door are frequent patient complaints'. ${ }^{2}$ During TEA the triceps insertion footprint is elevated off the ulna, and then reattached at the end of the procedure, as per the Bryan-Morrey approach. ${ }^{3-5}$ Recent advances in elbow designs are placing greater importance on surrounding soft-tissue to provide elbow stability. ${ }^{6}$ We speculate that reduction in elbow extension force and subsequent loss of range of motion against gravity following TEA may be partially due to damage to the distal medial and lateral triceps insertions.

The three components of the triceps muscles, medial, lateral, and long heads anatomically and physiologically work independently but synergistically to extend the forearm. There is an average discrepancy between the olecranon and the triceps central tendon leaving approximately $2.2 \mathrm{~mm}$ of the central tendon for independent attachments for the medial or lateral portions of the triceps. ${ }^{7}$ Additionally, Keener et al. ${ }^{7}$ reported a distinct lateral tricep portion that blends with the anconeus which we have seen in approximately $40 \%$ of our unpublished cadaveric dissections. Anatomical dissection has identified a thin visually discernible fascia that separates the medial portion from the common central attachment to the Olecranon. ${ }^{8}$ Physiologically the medial portion of the triceps and aconenus has been found to be most active during terminal elbow extension activities. ${ }^{9-11}$ In an isometric controlled study increased 
activation levels have been found to be significantly higher at $30^{\circ}$ and $10^{\circ}$ extended position than in the mid-positions of motion. ${ }^{12}$ These tasks give an indication of how the various portions of the triceps muscle function in a controlled laboratory setting, but triceps muscle activation during typical daily dynamic activities is not available. ${ }^{13}$ With the recent increase in TEA and importance of triceps muscle to regain normal function there needs to be a better understanding of how the individual triceps portion function during daily elbow extension activities. We hypothesized that the medial and lateral portions of the triceps will recruit more motor units in the terminal $30^{\circ}$ arc of extension relative to more flexed arcs of motion. Secondarily, we hypothesized that the medial and lateral portions will be more active than the central portion in the terminal $30^{\circ}$ of extension.

\section{Materials and methods}

\section{Subjects}

A sample of convenience of 20 healthy volunteers (mean age $30 \pm 7$ years old, height $173 \pm 11 \mathrm{~cm}$ and weight $68 \pm 4.4 \mathrm{~kg}$ ) consisting of 17 males participated in this study. Participants were excluded if they reported a musculoskeletal injury to the shoulder or elbow joints in the last 6 months requiring medical attention. Participants were also excluded if they reported a previous neurological disorder, arthritis, or an adhesive allergy. All participants were evaluated by an orthopedic surgeon to assure they met these criterions. All subject read and signed an IRB form approved at University of Kentucky prior to starting the testing procedures.

\section{Instrumentation}

The dominant arm indicated as the preferred throwing arm was tested. Two $50 \mathrm{~mm}$ indwelling electrodesa were embedded into each muscle studied using 27 gauge sterilized needles. ${ }^{14}$ The skin overlying each muscle location was cleaned with alcohol prior to needle electrode placement. The long head of the triceps was identified for insertion by measuring half the distance from the posterior acromion to the superior edge of the olecranon and $2 \mathrm{~cm}$ medial from this point, which we termed the central portion. ${ }^{15}$ The medial triceps, termed the medial portion, was identified $3 \mathrm{~cm}$ superior to the olecranon carefully avoiding the ulnar nerve during needle insertion. The skin overlying the lateral aspect of the proximal olecranon process, termed the lateral portion, $3 \mathrm{~cm}$ distal to the olecranon tip was identified for needle insertion (Figure 1) ${ }^{16}$ We describe the lateral triceps/ anconeus complex as the lateral portion of the triceps as Keener found that the lateral triceps muscle fibers ran continuous with the anconeus ${ }^{7}$. The placement of electrodes near the olecranon was used in order to represent muscle activity of the medial and lateral insertional extensions of the triceps. The two $50 \mathrm{~mm}$ indwelling electrodes were taped to the skin to minimize movement artifact. A surface ground $(\mathrm{Ag} / \mathrm{AgCl})$ electrode was placed on the opposite acromion. The electromyographical (EMG) signals were amplified with a gain of 1000 through a portable amplifier attached to the participant's waist to allow for freedom of movement. All data was collected at $2000 \mathrm{~Hz}$.

An electrogoniometer was applied to the participant's lateral forearm and humerus to synchronously measure elbow range of motion of each functional activity with the collection of EMG activity ${ }^{17}$. The electrogoniometer was calibrated by having the participant fully flex and extend the arm with the elbow angle measured with a standard goniometer simultaneously. The mean voltage collected during maximal elbow flexion and extension was converted to degrees of motion using a simple algebraic formula of (measured angle/mean voltage). This was performed so that all gomiometric data during functional tasks could be sub-divided into arcs of elbow motion.

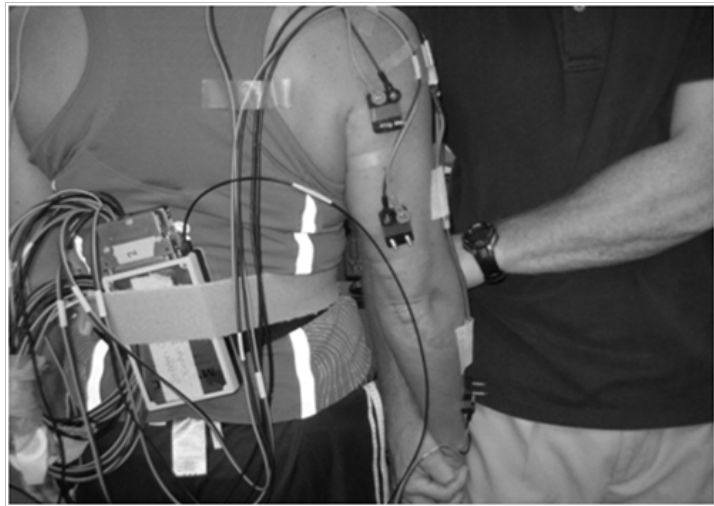

Figure I Instrumentation and insertion locations of fine wire EMG.

\section{Functional activities}

Three separate functional activities were performed. The order of functional activities was counterbalanced using a Latin square design to minimize fatigue affects from functional activity order. Each participant was given time to become familiar with the functional activity prior to data collection. Ten repetitions were collected for all functional activities. A metronome was used to control the rate of movement so that all activities were performed at $90^{\circ} \mathrm{sec}-1$. A minimum of two minutes rest was given between each set of a functional activity to allow for recovery. ${ }^{18}$

Supine extension functional activity was performed under three different loads $(0,1 \mathrm{~kg}$, and $2 \mathrm{~kg})$. The participant was positioned supine with their shoulder flexed to $90^{\circ}$ and their elbow flexed to $120^{\circ}$. Participants were instructed to extend their arm to full extension in synchrony with the metronome and then return to $120^{\circ}$ flexed position at their own pace. Ten trials were completed for each load (Figure 2 ). The overhead reach activity was performed in standing under three different loads $(0,1 \mathrm{~kg}$ and $2 \mathrm{~kg})$ using one of three plastic water bottles. The participant was instructed to lift the water bottle from waist level to overhead. Adjustable shelves were used to standardize starting position so that participants elbow was flexed to $90^{\circ}$ and upper shelf was positioned to assure complete elbow extension when placing bottle on the top shelf (Figure 3).

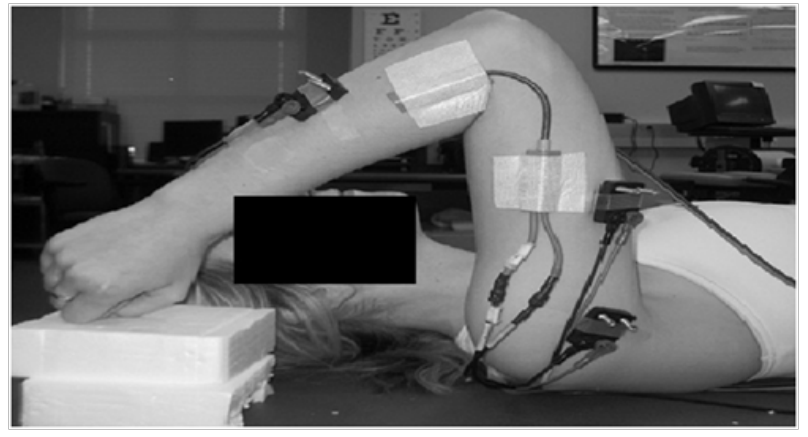

Figure 2 Supine extension activity with no load, shoulder flexed to $90^{\circ}$ with arm in starting position blocked to $120^{\circ}$ of elbow flexion. 


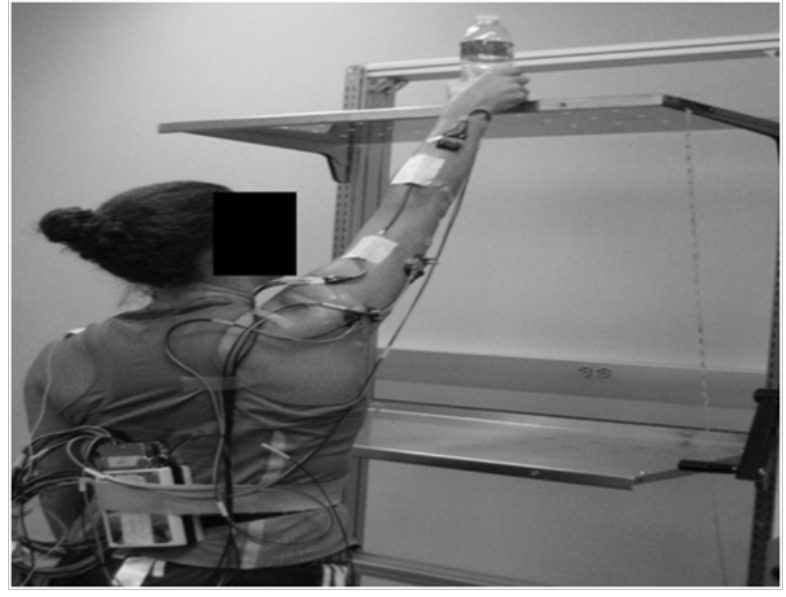

Figure 3 Overhead reach functional activity with no load. Patient is in the extension portion of the task in front of adjustable shelving.

The push functional activities were performed by pushing a computer mouse across a table-top $(0 \mathrm{~kg})$ to represent the unloaded condition and to push open a door $(4.5 \mathrm{~kg})$ to represent a loaded condition. In both activities the participant's elbow began at $90^{\circ}$ and was then fully extended. The load to push the door was measured with a calibrated hand-held dynamometer and was determined to be $4.5 \mathrm{Kg}$.

\section{EMG Data reduction}

All raw data was corrected for potential DC offsets. A band pass filter set at $10-1000 \mathrm{~Hz}$ was applied to all EMG data. ${ }^{19}$ The electrogoniometer kinematic data was filtered with a low pass Butterworth filter set at $6 \mathrm{~Hz}$ with 2nd order zero lag. All data were recorded, stored, and analyzed with proprietary software. Two, 5 second maximal voluntary isometric contractions (MVIC) were performed with elbow flexed to $20^{\circ}$ with a one minute rest between contractions. This position was found to generate the greatest muscular recruitment in pilot testing. The highest $500 \mathrm{~ms}$ root mean squared
(RMS) amplitude measured represented 100\% EMG activity. All EMG activity collected during functional activity was sub-divided into $30^{\circ}$ arcs with each muscle's RMS amplitude normalized to a \%MVIC. A five second resting baseline was collected with participants standing arms relaxed at their sides. This voltage was subtracted from all EMG data collected in order to remove background ambient noise. ${ }^{20,21}$ The middle four trials of the ten recorded trials were averaged to represent the recorded activity for a functional activity and used for statistical analysis. A trial was discarded and replaced if the elbow velocity was not at $90^{\circ}$ sec-1 as alterations in velocity of limb motion can impact EMG amplitudes. ${ }^{22,23}$

\section{Statistical analysis}

To examine the independent variables of angle, muscle, and load on the dependent measure of EMG activity for the three separate functional activities, three separate repeated measures ANOVA models were applied. The overhead reach functional activity had three within factors: muscle (lateral, central, \& medial triceps muscles), angle $\left(90-60^{\circ}, 60-30^{\circ}, 30-0^{\circ}\right)$, and load $(0,1,2 \mathrm{Kg})$. The push functional activity had the exact same design with only two load levels ( 0 and $4.5 \mathrm{Kg}$ ). The supine elbow extension functional activity had the same design as the overhead reach with one additional arc of motion (120$90^{\circ}$ ). Statistical significance was set a priori $\mathrm{p} \leq .05$ for all tests. Any significant differences found by the ANOVA were further investigated with a Bonferroni post-hoc with alpha level $\leq .05$.

\section{Results}

The descriptive data of normalized EMG activity for all functional activities is presented in the (Table 1). The medial triceps was activated most across all functional tasks with a maximal activation of $54 \pm 11 \%$ MVIC during the terminal arc of supine extension whereas the central portion was activated least throughout all exercises with a maximal activation of $28 \pm 7 \%$ MVIC during the middle two arcs of the same task. The lateral portion showed a maximal activation of $44 \pm 11 \%$ MVIC during the terminal arc of overhead reaching activity.

Table I Descriptive EMG amplitudes for all elbow extension functional activities in $30^{\circ}$ arcs

\begin{tabular}{|c|c|c|c|c|c|c|c|c|c|}
\hline & & \multicolumn{2}{|c|}{$1200-900$} & \multicolumn{2}{|c|}{$900-600$} & \multicolumn{2}{|c|}{$600-300$} & \multicolumn{2}{|c|}{$30 o-0 o$} \\
\hline & & Mean & $\mathrm{Cl}_{95}$ & Mean & $\mathrm{Cl}_{95}$ & Mean & $\mathrm{Cl}_{95}$ & Mean & $\mathrm{Cl}_{95}$ \\
\hline \multicolumn{10}{|c|}{ Supine Extension } \\
\hline \multirow[t]{3}{*}{ Unladed } & Central & 6 & $4-8 \%$ & 7 & $5-9 \%$ & 7 & $4-10 \%$ & 9 & $5-13 \%$ \\
\hline & Lateral & 22 & $15-29 \%$ & 23 & $16-30 \%$ & 23 & $16-30 \%$ & 20 & $13-27 \%$ \\
\hline & Medial & 20 & $10-30 \%$ & 24 & $15-32 \%$ & 27 & $20-34 \%$ & 36 & $27-45 \%$ \\
\hline \multirow[t]{3}{*}{$1 \mathrm{~kg}$} & Central & 13 & $9-17 \%$ & 14 & $10-18 \%$ & 14 & $10-18 \%$ & 13 & $9-17 \%$ \\
\hline & Lateral & 28 & $21-35 \%$ & 29 & $22-36 \%$ & 30 & $22-38 \%$ & 25 & $17-33 \%$ \\
\hline & Medial & 27 & $17-37 \%$ & 30 & $21-39 \%$ & 34 & $25-43 \%$ & 43 & $35-52 \%$ \\
\hline \multirow[t]{3}{*}{$2 \mathrm{~kg}$} & Central & 24 & $18-30 \%$ & 28 & $21-35 \%$ & 28 & $21-35 \%$ & 26 & $19-33 \%$ \\
\hline & Lateral & 36 & $28-44 \%$ & 36 & $19-43 \%$ & 34 & $27-41 \%$ & 30 & $21-39 \%$ \\
\hline & Medial & 41 & $31-51 \%$ & 46 & $36-56 \%$ & 49 & $39-59 \%$ & 54 & $43-65 \%$ \\
\hline \multicolumn{10}{|c|}{ Overhead Reach } \\
\hline \multirow[t]{3}{*}{ Unloaded } & Central & ND & ND & 5 & $1-9 \%$ & 6 & $2-10 \%$ & 6 & $2-10 \%$ \\
\hline & Lateral & ND & ND & 29 & $21-37 \%$ & 31 & $23-39 \%$ & 32 & $34-40 \%$ \\
\hline & Medial & ND & ND & 22 & $12-32 \%$ & 33 & $19-47 \%$ & 38 & $26-50 \%$ \\
\hline
\end{tabular}


Table Continued..

\begin{tabular}{|c|c|c|c|c|c|c|c|c|c|}
\hline & & \multicolumn{2}{|c|}{$1200-900$} & \multicolumn{2}{|c|}{$900-600$} & \multicolumn{2}{|c|}{$600-300$} & \multicolumn{2}{|c|}{$30 o-0 o$} \\
\hline & & Mean & $\mathrm{Cl}_{95}$ & Mean & $\mathrm{Cl}_{95}$ & Mean & $\mathrm{Cl}_{95}$ & Mean & $\mathrm{Cl}_{95}$ \\
\hline \multirow[t]{3}{*}{$1 \mathrm{~kg}$} & Central & ND & ND & 6 & $2-10 \%$ & 7 & $3-11 \%$ & 8 & $4-12 \%$ \\
\hline & Lateral & ND & ND & 33 & $24-42 \%$ & 35 & $26-44 \%$ & 40 & $30-50 \%$ \\
\hline & Medial & ND & ND & 29 & $20-38 \%$ & 35 & $26-44 \%$ & 42 & $32-52 \%$ \\
\hline \multirow[t]{3}{*}{$2 \mathrm{~kg}$} & Central & ND & ND & 10 & $6-14 \%$ & 12 & $7-17 \%$ & 11 & $6-16 \%$ \\
\hline & Lateral & ND & ND & 40 & $30-50 \%$ & 41 & $31-51 \%$ & 44 & $33-55 \%$ \\
\hline & Medial & ND & ND & 35 & $25-45 \%$ & 42 & $31-53 \%$ & 49 & $35-63 \%$ \\
\hline \multicolumn{10}{|l|}{ Push } \\
\hline \multirow[t]{3}{*}{ Unloaded } & Central & ND & ND & I & $-1-3 \%$ & 2 & $0-4 \%$ & 3 & $1-5 \%$ \\
\hline & Lateral & ND & ND & 10 & $6-14 \%$ & 15 & $10-20 \%$ & 17 & II-25\% \\
\hline & Medial & ND & ND & 7 & $0-14 \%$ & 10 & $3-17 \%$ & 25 & $17-33 \%$ \\
\hline \multirow[t]{3}{*}{ Loaded } & Central & ND & ND & 3 & $1-5 \%$ & 3 & $1-5 \%$ & 6 & $2-10 \%$ \\
\hline & Lateral & ND & ND & 18 & $13-23 \%$ & 17 & $12-22 \%$ & 21 & $14-28 \%$ \\
\hline & Medial & ND & ND & 17 & |l-25\% & 20 & $9-31 \%$ & 29 & $22-36 \%$ \\
\hline
\end{tabular}

All EMG data is reported as mean with $95 \%$ confidence intervals in the unit of $\%$ MVIC

ND, No data recorded for this angle.

The overhead reach functional activity revealed no significant muscle by angle interaction but approached significance $(\mathrm{p}=.06)$. Main effects were found for muscle $(\mathrm{p}<.001)$ and angle $(\mathrm{p}=.001)$. A Bonferroni post-hoc analysis for muscle, revealed that the medial $(36 \pm 18 \% \mathrm{MVIC})$ and lateral triceps portion $(36 \pm 22 \% \mathrm{MVIC})$ generated more activity than the central portion $(8 \pm 8 \% \mathrm{MVIC})$ with this activity across all angles and loads $(\mathrm{p}<.001)$. A Bonferroni posthoc analysis for angle, revealed that the $90-60^{\circ}$ arc generated the least EMG activity ( $23 \pm 10 \% \mathrm{MVIC})$ across all three muscles compared to $60-30^{\circ}(27 \pm 11 \% \mathrm{MVIC}, \mathrm{p}=.002)$ and $30-0^{\circ}(30 \pm 12 \% \mathrm{MVIC}, \mathrm{p}=.006)$.
The push functional activity revealed a significant two-way interaction (muscle by angle) that as elbow angle approached full extension a significant increase in EMG activity was observed $(p=.006)$. Bonferroni post-hoc analysis demonstrated that the medial and central triceps exhibited significantly more activation in the final $30^{\circ}$ compared to all other arcs (Figure 4 ). The lateral triceps was more active than the central triceps for all arcs of motion $(\mathrm{p} \leq .001)$, while the medial triceps was significantly more active than the central triceps only at the terminal $30^{\circ}$ arc $(\mathrm{p}<.001)$ (Figure 4$)$.

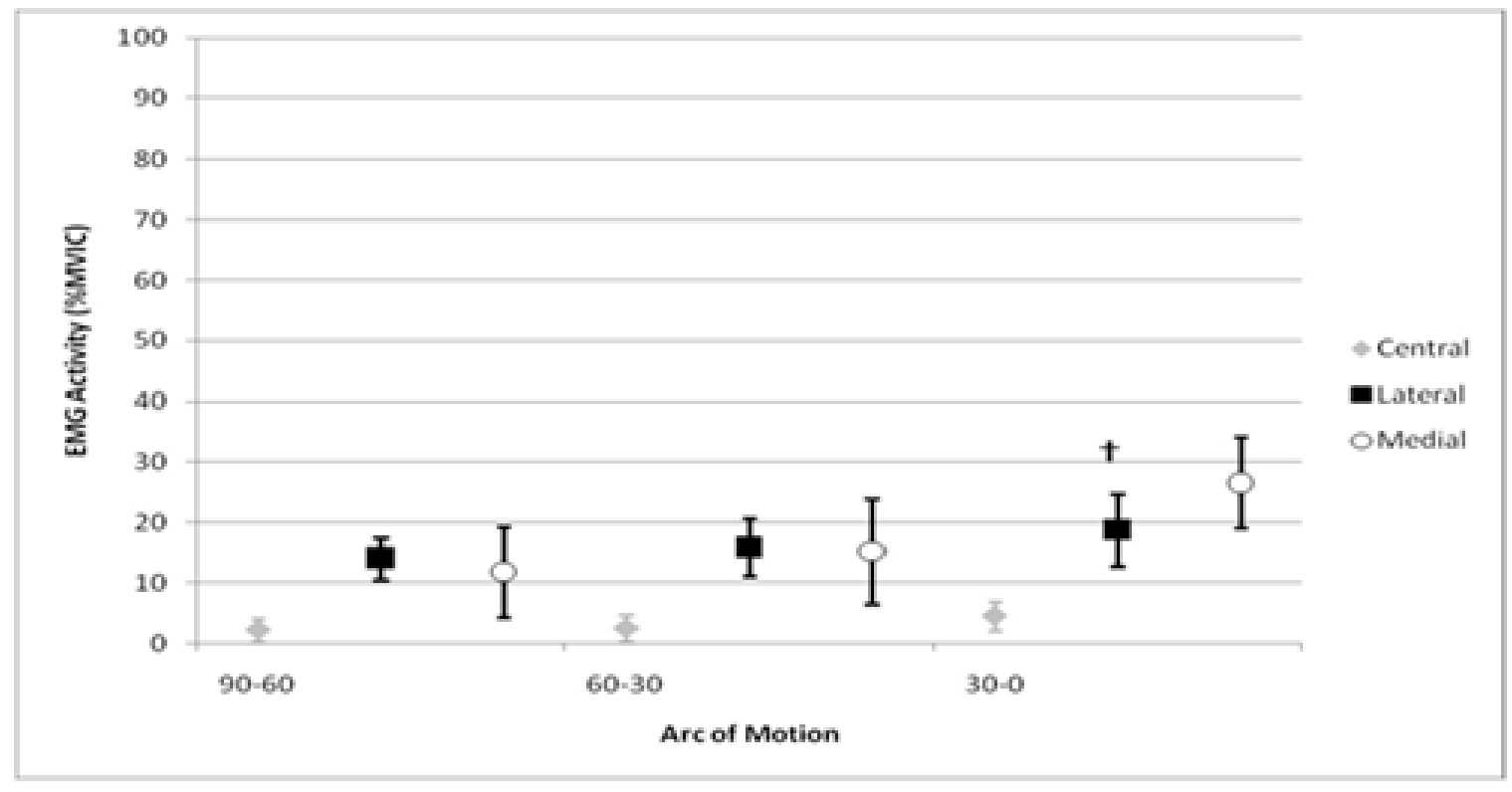

Figure 4 Push Functional Activity results demonstrating significant increase in medial and central muscular activity in the last $30^{\circ}$ arc of motion $(*)$. The lateral triceps was relatively constant throughout elbow extension but was significantly more active than the central portion ( $\dagger$ ), while the medial triceps was significantly more active than the central portion in the terminal $30^{\circ}$ arc $(\ddagger)$. The error bars represent $95 \%$ confidence intervals around the average EMG amplitude. 
The supine extension functional activity revealed a significant twoway interaction (muscle by angle) that as elbow angle approached full extension a significant increase in EMG activity was observed $(\mathrm{p}=.003)$. The Bonferroni post-hoc analysis demonstrated that the medial triceps was significantly more active in the final $30^{\circ}$ arc than all other angles $(\mathrm{p}<.05)$ (Figure 5). Additionally, the medial and lateral triceps generated significantly more EMG activation than the central triceps at $120-30^{\circ} \operatorname{arcs}(\mathrm{p} \leq .04)$ At the $30-0^{\circ}$ arc the medial triceps was significantly more active than both the central and lateral triceps $(\mathrm{p}<$ .01) (Figure 5).

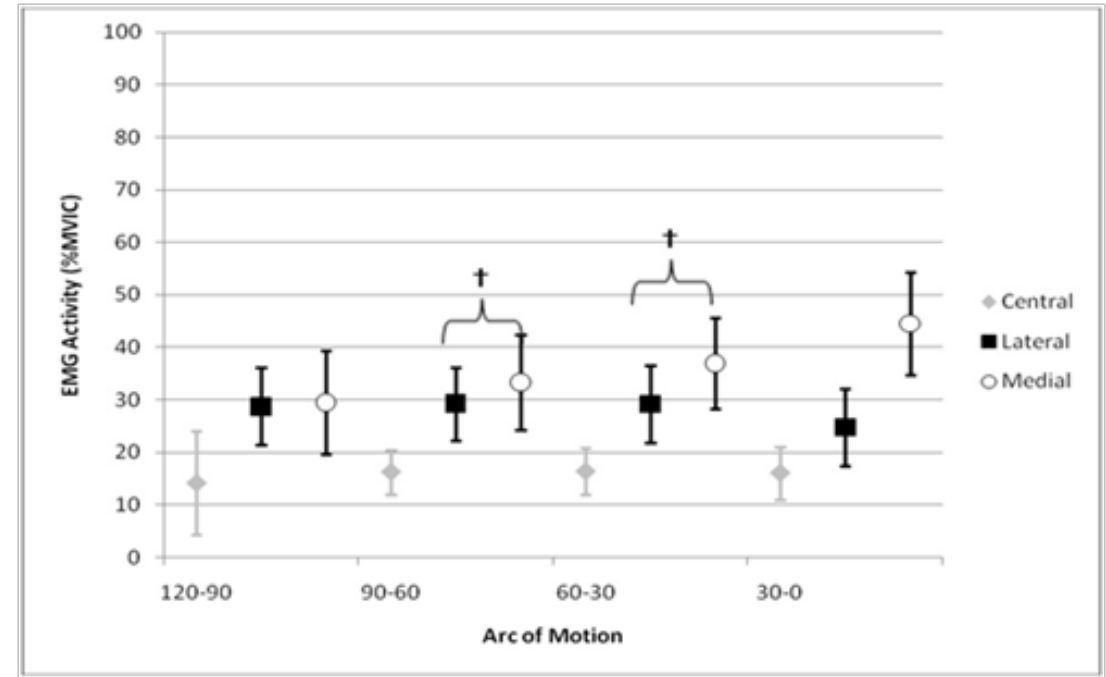

Figure 5 Supine Extension Functional Activity results demonstrating significant more EMG activity in the last $30^{\circ}$ arc of motion in the medial triceps $(*)$. The medial and lateral triceps generated significantly more EMG activity than the central triceps at $120-90^{\circ}, 90-60^{\circ}$, and $60-30^{\circ}$ arcs $(\dagger)$. The medial triceps was significantly more active than both the central and lateral triceps at the terminal $30^{\circ}$ arc ( $\left.\ddagger\right)$. The error bars represent $95 \%$ confidence intervals around the average EMG amplitude.

\section{Discussion}

This study analyzed the activation amplitudes of the central, medial and lateral portions of the triceps muscle during simple reaching functional activities with relatively low loads similar to what a patient may need to do to carryout daily life. We hypothesized that there would be greater muscular recruitment of the medial and lateral triceps in the terminal $30^{\circ}$ arc of extension relative to more flexed arcs of motion. This was partially supported as the medial triceps muscle typically increased motor unit activation level in the terminal phase of extension in two of the activities. However, the lateral triceps demonstrated a pattern of constant moderate activity as previously reported. ${ }^{11}$ Secondly, we hypothesized that the medial and lateral portions would be more active than the central portion in the last $30^{\circ}$ of extension which was partially supported. The lateral and medial muscles demonstrated constantly more EMG activation than the central portion throughout all angles and activities. Only during the push activity was there significantly greater EMG activity in both muscles over the central triceps in the terminal $30^{\circ}$ arc (Figure 4).

The medial portion did show significant increases in activation in the last $30^{\circ}$ arc for 2 of the 3 functional activities and appeared to be the primary extensor of the posterior muscle group while the lateral portion was observed as more of a stabilizer with its motor unit activation level remaining relatively constant throughout the extension motion. Travill ${ }^{24}$ and Basmajian et al. ${ }^{9}$ also considered the medial portion to be the primary elbow extensor and suggested that the lateral and long heads are used as reserves. Naito et al. ${ }^{11}$ revealed similar results with an indwelling EMG analysis of the anconeus and the three triceps portions during elbow extension using a $1.2 \mathrm{~kg}$ load. They reported that EMG amplitudes in the medial and lateral portions of the triceps as compared to the central aspect, increased near full extension. Unfortunately these researchers did not normalize their data so direct comparison of amplitudes cannot be made, but their findings reveal similar activation patterns of the triceps to the current study. The lateral triceps activation amplitude remained relatively steady throughout all arcs of extension activities agreeing with previous reports. ${ }^{11}$ This stabilization nature of the lateral triceps is prevalent in our study as well as others. ${ }^{11,25,26}$ The lateral triceps is predisposed to activation due to gravity acting on the ulna as it is abducted creating the carrying angle of the elbow which may impact these results. ${ }^{27}$ The concept of mono-articular muscles, such as the medial and lateral triceps working primarily during concentric contractions has been previously established in the lower extremity. ${ }^{28}$ The roles of the bi-articular muscles during cycling were found to function more as controllers and to regulate forces during more complex motions. ${ }^{28}$ This phenomenon appears to be occurring in these simple reaching tasks as the mono-articular muscles of the medial and lateral triceps were primarily activated as previously reported. ${ }^{9}$ The bi-articular central triceps portion was only used in reserve when the demand was higher or more control was needed as observed with increased muscular activation of supine extension with a $2 \mathrm{~kg}$ load (Table 1).

The current study contradicts previous isometric findings indicating that elbow joint angle had no significant effect on EMG amplitudes. It has been previously suggested that elbow joint angle has no significant effect on EMG amplitudes when tested isometrically. ${ }^{12}$ Unfortunately, the researchers did not specify the triceps muscle tested and from the published figure appears that only the central portion of the triceps was instrumented. ${ }^{12}$ Similar findings of no relationship between angle and activation were reported when subjects performed isometric contractions ranging from $40-120^{\circ} .{ }^{29}$ In both of the previous studies isometric contractions the authors concluded that the triceps work synergistically but are not independent of each other. However in dynamic studies ${ }^{11,26}$ researchers have indicated independent muscular activation patterns with amplitudes or onset of activation 
difference between musculature. These results indicate that different motor activation patterns are working when isometric versus dynamic activities are investigated. The current research study supports previous dynamic findings and adds functional movement activation patterns indicating a bias of the medial and lateral triceps portions as critical components for obtaining full elbow extension.

Anatomical considerations of these results have rehabilitation implications. The medial portion of the triceps has been observed to extend parallel to the common central triceps tendon and attach to the olecranon8 and can be elevated during a dorsal surgical approach. ${ }^{30}$ During elevation of the medial and lateral muscle fibers motor units are potentially damaged, resulting in limited extension arc that is observed in post-operative TEA patients. The surgical implications are beyond the scope of this paper. However, to regain full elbow extension it is very evident from these results that the careful repair and rehabilitation of medial and lateral portions of the triceps are paramount.

\section{Limitations}

For the purposes of the current study we considered the anconeus to represent the lateral triceps due to the recent anatomical findings in the literature that this muscle represents the functional unit of the lateral triceps. ${ }^{7}$ This investigation only examined healthy subjects to investigate normal electrophysiological responses to these functional activities so our study results cannot be extrapolated to an injured population with certainty. Further, this study used relatively light loads to represent more functional activities. Additional investigation using greater loads would shed light on how the central triceps is recruited throughout elbow extension under more loads. Finally, research prior to and following surgical intervention is necessary to determine the specific roles of the triceps musculature in a patient population.

\section{Conclusion}

This study indicates that the distal portion of the medial triceps significantly increases muscle activation amplitudes in the $30^{\circ}-0^{\circ}$ arc in the push and overhead extension activities suggesting that this muscle attachment and function is critical for terminal elbow extension. The lateral portion is activated consistently throughout the extension motion and acts as a dynamic stabilizer during extension activities. The central portion is minimally activated under the current study conditions with low resisted loads. The clinical relevance of our findings should encourage exposures for elbow surgery to avoid reflecting the muscular insertions of the medial and lateral heads from the olecranon process.

\section{Suppliers}
A. (California Fine Wire Co, Grover Beach, CA)
B. (Myopac, Run Technologies, Mission Viejo, CA)
C. (SG110, Biometrics, Ladysmith, VA, USA)
D. (Datapac, Run Technologies, Mission Viejo, CA)

\section{References}

1. Voloshin I, Schippert DW, Kakar S, et al. Complications of total elbow replacement: a systematic review. J Shoulder Elbow Surg. 2011;20(1):158-168.

2. Celli A, Arash A, Adams RA, et al. Triceps insufficiency following total elbow arthroplasty. J Bone Joint Surg Am. 2005;87(9):1957-1964.
3. Hildebrand KA, Patterson SD, Regan WD, et al. Functional Outcome of Semiconstrained Total Elbow Arthroplasty. J Bone Joint Surg Am. 2000;82-A(10):1379-1386.

4. Gill DR, Cofield RH, Morrey BF. Ipsilateral total shoulder and elbow arthroplasties in patients who have rheumatoid arthritis. J Bone Joint Surg Am. 1999;81(8):1128-1137.

5. Morrey BF, Bryan RS, Dobyns JH, et al. Total elbow arthroplasty. A five-year experience at the Mayo Clinic. J Bone Joint Surg Am. 1981;63(7):1050-1063.

6. O’Driscoll SW, An KN, Korinek S, et al. Kinematics of semi-constrained total elbow arthroplasty. J Bone Joint Surg. 1992;74(2):297-299.

7. Keener JD, Chafik D, Kim HM, et al. Insertional anatomy of the triceps brachii tendon. J Shoulder Elbow Surg. 2010;19(3):399-405.

8. Madsen M, Marx RG, Millett PJ, et al. Surgical anatomy of the triceps brachii tendon: anatomical study and clinical correlation. Am J Sports Med. 2006;34(11):1839-1843.

9. Basmajian JV. Recent advances in the functional anatomy of the upper limb. Am J Phys Med. 1969;48(4):165-177.

10. Travill AA. Electromyographic Study of the Extensor Apparatus of the Forearm. Anat Rec. 1962;144:373-376.

11. Naito A, Shimizu Y, Handa Y, et al. Functional anatomical studies of the elbow movements. I. Electromyographic (EMG) analysis. Okajimas Folia Anat Jpn. 1991;68(5):283-288.

12. Doheny EP, Lowery MM, Fitzpatrick DP, et al. Effect of elbow joint angle on force-EMG relationships in human elbow flexor and extensor muscles. J Electromyogr Kinesiol. 2008;18(5):760-770.

13. Boon AJ, Spinner RJ, Bernhardt KA, et al. Muscle Activation Patterns in Snapping Triceps Syndrome. Arch Phys Med Rehab. 2007;88(2):239242 .

14. Kelly BT, Kadrmas WR, Speer KP. The manual muscle examination for rotator cuff strength: an electromyographic investigation. Am J Sports Med. 1996;24(5):581-588.

15. Cram JGK. Introduction to Surface Electromyography. Aspen, Colorado, USA, 1998.

16. Perrotto AO. Anatomical Guide for the Electromyographer. (3rd edn), In: Charles C Thomas (Ed.), Illinois, USA, 1994.

17. Morrey BF, Askew LJ, Chao EY. A biomechanical study of normal functional elbow motion. J Bone Joint Surg Am. 1981;63(6):872-877.

18. Yates JW, Kearney JT, Noland MP, et al. Recovery of dynamic muscular endurance. Eur J Appl Physiol Occup Physiol. 1987;56(6):662-667.

19. De Luca CJ. The use of surface electromyography in biomechanics. / Utilisation de 1 ' electromyographie de surface en biomecanique. J Appl Biomech. 1997;13:135-163.

20. Akkiraju P, Reddy DC. Adaptive cancellation technique in processing myoelectric activity of respiratory muscles. IEEE Trans Bio-Med Eng. 1992;39(6):652-655.

21. Reddy AS, Mohr KJ, Pink MM, et al. Electromyographic analysis of the deltoid and rotator cuff muscles in persons with subacromial impingement. J Shoulder Elbow Surg. 2000;9(6):519-523.

22. Heckathorne CW, Childress DS. Relationships of the surface electromyogram to the force, length, velocity, and contraction rate of the cineplastic human biceps. Am J Phys Med. 1981;60(1):1-19.

23. Bigland B, Lippold OC. The relation between force, velocity and integrated electrical activity in human muscles. J Physiol. 1954;123(1): $214-224$. 
24. Travill A, Basmajian JV. Electromyography of the supinators of the forearm. Anat Rec. 1961;139:557-560.

25. Basmajian JV, Griffin WR. Function of anconeus muscle. An electromyographic study. J Bone Joint Surg Am. 1972;54(8):1712-1714.

26. Le Bozec S, Maton B, Cnockaert JC. The synergy of elbow extensor muscles during dynamic work in man. I. Elbow extension. Eur J Appl Physiol Occup Physiol. 1980;44(3):255-269.

27. Gleason TF, Goldstein WM, Ray RD. The function of the anconeus muscle. Clin Orthop Rel Res. 1985;192:147-148.
28. van Ingen Schenau GJ, Dorssers WM, Welter TG, et al. The control of mono-articular muscles in multi joint leg extensions in man. $J$ Physiol. 1995;484(Pt 1):247-254.

29. Le Bozec S, Maton B, Cnockaert JC. The synergy of elbow extensor muscles during static work in man. Eur J Appl Physiol Occup Physiol. 1980;43(1):57-68.

30. Muller LP, Kamineni S, Rommens PM, et al. Primary total elbow replacement for fractures of the distal humerus. Oper Orthop Traumatol. 2005; 17(2):119-142. 